\title{
Influence of chitosan coatings with rosemary essential oil on mechanical and physical properties of packaging paper
}

\begin{abstract}
Recently, coated paper substrates have been used in a wide range of packaging applications. In this research, we present a chitosan with rosemary essential oil, paper coating as water and possible repellent resistant solution on biological basis. The aim of this research was to coat two different uncoated (also calendared) papers with a bio-based coating solution and to analyse mechanical, physical properties, resistance of coating and print ink. The resulting coated chitosan-rosemary oil, papers showed remarkable water resistance ( $\mathrm{Cobb}_{60}$ values 5.18 and $4.55 \mathrm{~g} / \mathrm{m}^{2}$ ). The good mechanical properties of the coated papers increased after the coating treatment. Namely, elongation at break and tear strength improved due to the structure of the coating itself. The resistance of coatings on printed surfaces also showed sufficient results for further packaging applications.
\end{abstract}

\section{KEY WORDS}

surface, packaging, materials, durability, bio based

\author{
Urška Vrabič Brodnjak (D) \\ Katarina Tihole \\ University of Ljubljana, Faculty of \\ Natural Sciences and Engineering, \\ Department of Textiles, Graphic Arts \\ and Design, Ljubljana, Slovenia
}

Corresponding author: Urška Vrabič Brodnjak e-mail: urska.vrabic@ntf.uni-lj.si

First recieved: 17.03.2020. Accepted: 30.04 .2020$.

\section{Introduction}

There is a long way of the packaging product from the manufacturing plant to our home, as it exchanges several environments with different hygienic conditions as well as the effects of the external environment (temperature, humidity, handling of the products, etc.) All these are excellent opportunities for product contamination, especially with insects (and microbes), which can cause enormous material and consequently financial losses. In our research, a suitable material was selected and a repellent was applied to test the effectiveness of coatings on graphic products. In recent years, essential oils (EOs) have been studied as additives in films and coatings (Rodriguez, Batlle \& Nerin, 2007; Atarés \& Chiralt, 2016; Yuan, Chen \& Li., 2016; Guerrero et al., 2020). Due to their properties, essential oils have a hydrophobic character, reduce the water vapour permeability of films and coated paper. Furthermore, some studies have shown that they have a positive influence on tensile strength, optical and structural properties (Khwaldia, Arab-Tehrany \& Desobry, 2010; Sánchez-González et al., 2011; Atarés \& Chiralt, 2016).

Some studies have shown that essential oils should have a high potential as natural pesticides (Mossa, 2016; Nollet \& Rathore, 2017; Upadhyay et al., 2018). Some examples of studies have shown that essential oils have already been used effectively in packaging materials as a natural insecticide for pests (repellent, digestive, growth inhibiting) (Licciardello et al., 2013; Ribeiro-Santos et al., 2017; Stejskal et al., 2017; Ju et al., 2019; Lee et al., 2019). Molecules in EOs that act on insects as mentioned above are considered rapidly non-toxic. Even with EOs it is not possible to replace all synthetic insect repellents for the time being, but some studies have shown that EOs are sufficient for certain insects such as $\mathrm{S}$. zeamais, mealworm beetles, Tenebrio molitor Linnaeus, etc. (Plata-Rueda et al., 2017; Lopez et al., 2018; Tavares et al., 2018).

The current use of synthetic chemicals to control insects raises many concerns for the environment and human health, as there are alternative uses for natural products 
that are also effective but more environmentally friendly (Tavares et al., 2018; Da Silva \& Ricci-Júnior, 2020).

Among the alternatives are bio-pesticides, whose market value has risen to $\$ 3$ billion in 2018 and is expected to rise to $\$ 6.4$ billion by 2023 (Markets \& Markets, 2020). Safety and regulatory issues have played an important role in this growth, as the use of bio-pesticides EO in Europe, Japan and North America as an ingredient in medicines has increased confidence in their safety. Bio-pesticides involve a variety of control methods, from microbial to plant based. Among the herbal methods, EOs play a major role. During evolution, aromatic plants have developed many important chemical compounds to defend against the herbivorous insect.

On the other hand, there is chitosan, as a cationic polysaccharide consisting of (1,4)-linked (1,4)-aminodesoxy-b-D-glucan deacetylated from chitin. Chitosan has been shown to have multiple biological activities, including antioxidant, non-allergic and antimicrobial, and it is considered a suitable biopolymer for edible coatings and films (Vrabič Brodnjak, 2017; Wang, Qian \& Ding, 2018). Chitosan coatings can be used both as drug carriers and as EOs. Many EOs such as oregano, thyme, rosemary, basil and cinnamon are gaining popularity in bio-based coatings for various packaging purposes.

The aim of our research was to produce chitosan coatings with incorporated rosemary essential oil for packaging products that can be used as natural repellents. Based on the use in graphic products, the influence of coatings on paper was evaluated in terms of mechanical, physical and printing properties.

\section{Materials and methods}

\section{Materials}

Two uncoated papers, with different grammage were used:

- sample 1: uncoated (not calendared), white, paper, with specified grammage $330 \mathrm{~g} / \mathrm{m}^{2}$

- sample 2: uncoated and calendared on one side, white, paper, with specified grammage $250 \mathrm{~g} / \mathrm{m}^{2}$

Coating solution was prepared with rosemary essential oil (Bergland GmbH, Germany), chitosan (Sigma-Aldrich Chemie GmbH, Germany), acetic acid (Sigma-Aldrich Chemie GmbH, Germany) and glycerol (Sigma-Aldrich Chemie GmbH, Germany).

\section{Preparation of coating dispersion and coating procedure}

Chitosan solution was prepared by dissolving $2 \mathrm{~g}$ chitosan in $100 \mathrm{ml}$ of $2 \%$ acetic acid. To the solution, 50 $\mathrm{ml}$ of glycerol was added. The solution was mixed for 10 min, at stirred speed $800 \mathrm{rpm}$ and at $85^{\circ} \mathrm{C}$. After that the mixed solution was cooled to room temperature. After the mixing, solution was filtered through a polyester screen (mesh no. 140, mesh opening $160 \mu \mathrm{m}$ ) with aspiration to remove small lumps in the solution. When chitosan solution was filtered, $20 \mathrm{ml}$ of rosemary essential oil was added and stirred at room temperature.

After the solution was prepared, the coating with a coater (RKPrintcoat Instruments Ltd, Great Britain) was proceeded. Papers were coated with bio-based film forming solutions on a coating table at ambient temperature, using a $60 \mu \mathrm{m}$ blade. Afterwards, it was dried at $30{ }^{\circ} \mathrm{C}$ for 10 minutes. On each paper, $5 \mathrm{~g} / \mathrm{m}^{2}$ of solution was applied. For a comparison, the uncoated as well as coated papers were analysed in the research.

\section{Methods}

\section{Grammage, thickness}

Firstly, the grammage was determined, to obtain the amount of coating on all samples, which had an influence on other properties. Grammage was determined in accordance with the ISO 536 standard, where 10 samples of each paper were cut into size $10 \times 10 \mathrm{~cm}$ and weighed. The thickness of samples was measured with a precision digital micrometre (Mitutoyo Corporation, Japan), to the nearest $0.0001 \mu \mathrm{m}$ at 10 random locations on each paper. From the grammage and thickness, density and specific volume of paper were calculated, as described in the standard method ISO 534.

\section{Tensile properties and tear resistance}

Tensile strength (TS) and elongation at break (E) of papers were determined on a tensile testing machine Instron 6022 (Instron, USA) at standard atmosphere at $23^{\circ} \mathrm{C}$ and $50 \%$ of relative humidity. The cross speed head was $0.15 \mathrm{~mm} / \mathrm{s}$. Paper stripes of $18 \mathrm{~cm}$ in length and $1.5 \mathrm{~cm}$ in width were used and a minimum of ten probes for each sample was tested. During the sample stretching, several load and elongation data per second were recorded until the break of a sample occurred. Tear resistance was determined according to the standard ISO 1974-9290, where four samples of each paper were tested with the Elmendorf method. Tear resistance was determined in $\mathrm{N}$, as the force required to tear a sample after a cut was already started. All samples were tested at $23^{\circ} \mathrm{C}$ and $50 \% \mathrm{RH}$. After the measurement 
and determination of tensile strength and tear resistance, the tensile and tearing index were calculated.

\section{Water absorption capacity and capillary rise}

Water absorption capacity (the $\mathrm{Cobb}_{60}$ value, $\mathrm{g} / \mathrm{m}^{2}$ ) was determined as described in the standard method ISO 535 , where $100 \mathrm{ml}$ of water was in contact with the paper for 45 seconds and weight differences were compared. For each paper, ten sample tests were made. Capillary rise was determined as described in ISO 8787 (Klemm method). For each sample ten replicas were made.

\section{Resistance of coatings and colour}

The resistance of coatings, the cross-cut test was performed as described in standard ISO 2409:2013, using Byko-cut Universal instrument (BYK Additives \& Instruments, Germany). This test method was used for assessing the resistance of coatings and colours, to separation from substrates when a right-angle lattice pattern is cut into the coating, penetrating through to the substrate. The property measured by this empirical test procedure depends, among other factors, on the adhesion of the coating to either the preceding coat or the substrate.

\section{Results and discussion}

Grammage, thickness and density of coated and uncoated papers are summarised in Table 1. Grammage influences mostly the mechanical properties of the paper. The same is with thickness, which causes a difference in tensile strength, elasticity, bending and tearing stiffness, water barriers and optical prop- erties of the paper. It can be seen that $5 \mathrm{~g} / \mathrm{m}^{2}$ of bio-based coating solution was successfully applied to the surface of the samples. The thickness of a paper coating has a strong influence on many properties such as tensile properties, moisture, water vapour permeability and water absorption capacity.

\section{Tensile tests}

Tensile strength and elongation are summarised in Table 2. As paper is considered an anisotropic material, since fibres are aligned in the direction of travel in the papermaking machine (i.e. MD direction) and across the fibre alignment called cross-machine direction (i.e. CD direction), tests were performed in both directions. Tensile strength and elongation at break are very important for packaging materials, due to the specific handling and shipping of the products.

Polysaccharides blends with other polymers, in different ratios can improve mechanical properties as well (Vrabič Brodnjak, 2017). Combination of chitosan and rosemary essential oil coating had an effect on lower tensile strength but higher elongation at break, compared to uncoated samples. This indicated that combination of these two polymers governed the structural change and the polymer matrix became more flexible. Especially at uncoated sample 1, which had higher tensile strength as coated, but lower elongation. Sample 2 had as uncoated sample lower values of tensile strength and elongation as sample 1.

The tear resistance determines the force applied during the tearing procedure. It indicates the behaviour of paper and it is important in packaging papers,

Table 1

Results of grammage, density and thickness of uncoated and coated sample 1 and 2 .

\begin{tabular}{l|c|c}
\hline & Sample 1 & Sample 2 \\
\hline Grammage $\left[\mathrm{g} / \mathrm{m}^{2}\right]-$ uncoated & $330 \pm 1.0$ & $250 \pm 0.5$ \\
\hline Grammage $\left[\mathrm{g} / \mathrm{m}^{2}\right]$ - coated & $335 \pm 0.4$ & $255 \pm 0.4$ \\
\hline Density - uncoated $\left[\mathrm{kg} / \mathrm{m}^{3}\right]$ & $569 \pm 0.5$ & $781 \pm 2.0$ \\
\hline Density - coated $\left[\mathrm{kg} / \mathrm{m}^{3}\right]$ & $531 \pm 1.0$ & $689 \pm 1.0$ \\
\hline Thickness $[\mathrm{mm}]-$ uncoated & $0.58 \pm 0.4$ & $0.32 \pm 0.3$ \\
\hline Thickness $[\mathrm{mm}]-$ coated & $0.63 \pm 0.2$ & $0.37 \pm 0.2$ \\
\hline
\end{tabular}

Table 2

Results of tensile strength, elongation and tear resistance of uncoated and coated sample 1 and 2

\begin{tabular}{l|c|c|c|c}
\hline & sample 1-uncoated & sample 1- coated & sample 2-uncoated & sample 2 -coated \\
\hline Tensile strength [MPa] -MD & $222.00 \pm 0.40$ & $209.02 \pm 0.50$ & $187.54 \pm 0.50$ & $179.46 \pm 0.02$ \\
\hline Tensile strength [MPa] -CD & $123.00 \pm 0.70$ & $111.23 \pm 0.40$ & $109.91 \pm 0.20$ & $90.62 \pm 0.40$ \\
\hline Elongation [\%]-MD & $2.00 \pm 0.05$ & $2.58 \pm 0.05$ & $1.30 \pm 0.09$ & $1.07 \pm 0.03$ \\
\hline Elongation [\%]-CD & $5.20 \pm 0.60$ & $6.46 \pm 0.10$ & $3.20 \pm 0.30$ & $2.94 \pm 0.06$ \\
\hline Tear resistance [N] -MD & $335 \pm 0.76$ & $361 \pm 0.54$ & $247 \pm 0.27$ & $280 \pm 0.32$ \\
\hline Tear resistance [N] - CD & $262 \pm 0.29$ & $282 \pm 0.67$ & $206 \pm 0.93$ & $244 \pm 0.58$ \\
\hline
\end{tabular}


where the toughness and shock absorption are very important factors. The fact is that fillers and additives improve tear strength, as it tends to distribute the stress over the whole over long, cellulose fibres in the paper. The tear resistance was the highest at coated sample 1, compared to coated sample 2.

The grammage of uncoated and coated papers were different; therefore, using tensile strength and tear indices represents the real effect and are presented in Figure 1 and 2. The tensile and tear indices for all tested samples were determined in CD (Figure 2) and MD (Figure 1) directions. As expected, the values of tensile and tear indices are higher at samples in MD direction than in $\mathrm{CD}$ direction. Coated samples had the highest tear and tensile index in both directions, compared to uncoated.

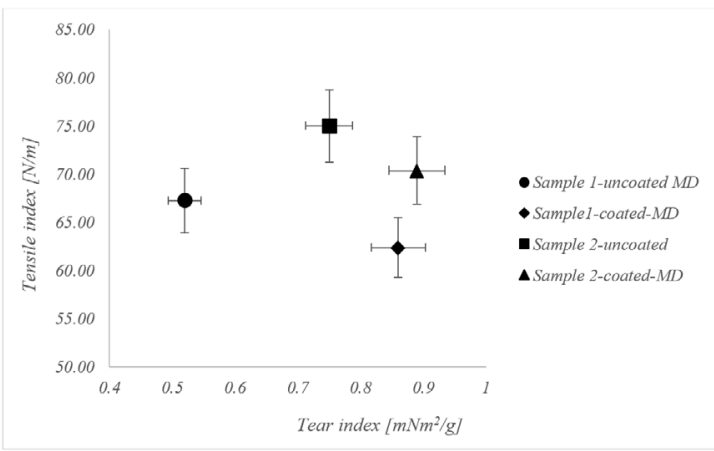

» Figure 1: Tensile and tear index of samples in MD direction

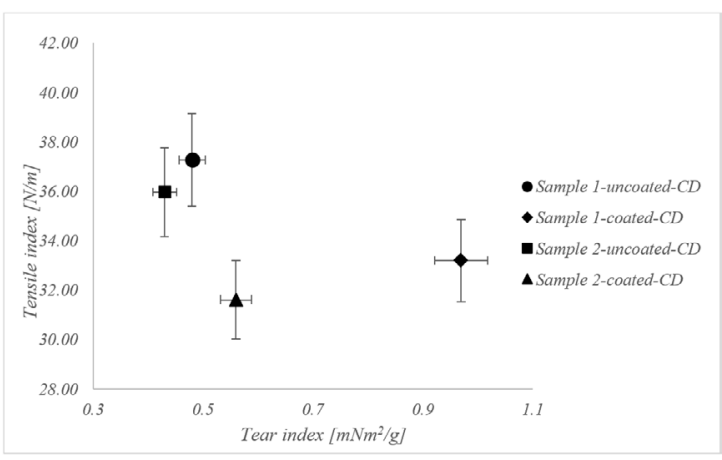

» Figure 2: Tensile and tear index of samples in CD direction

\section{Water absorption capacity and capillary rise}

To analyse hydrophilic/hydrophobic nature of the paper coatings, their water absorptiveness and capillary rise was determined as seen in Figure 3 and 4 .

As expected, the poorest water barrier properties had uncoated paper. At coated papers, the best absorptiveness achieved uncoated, non-calendared sample 1. It can be observed that hydrophobicity of the papers was enhanced with the addition of coatings. It is known, that chitosan has poor water barrier properties, due to its hydrophilicity, but on the other hand the addition of the essential oil improved water barrier properties of coated samples. The same trend was observed at capillary rise (Figure 4), where the highest values were at sample 1. Calendared, non coated sample 2 had lower values of capillary rise (11.5 in MD and 10 in CD), compared to sample 1. As expected, the addition of the coatings improved water barriers on both samples.

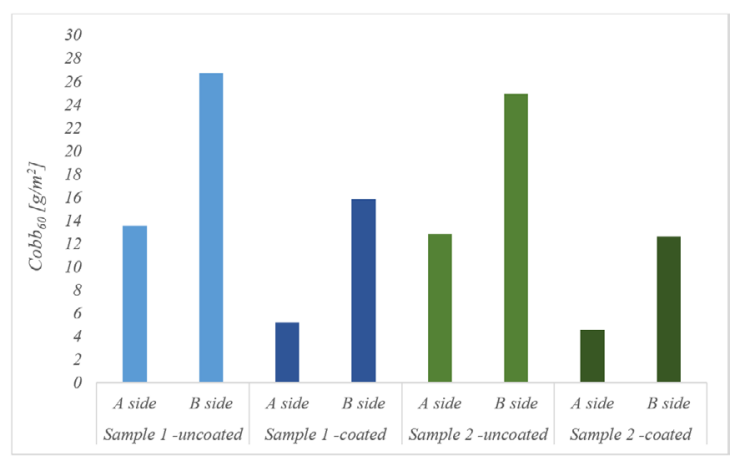

» Figure 3: Water absorptivness (Cobb value) of samples on $A$ and $B$ side

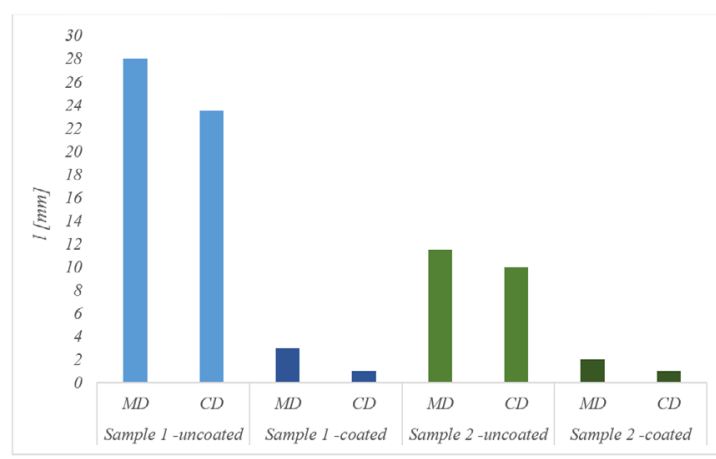

» Figure 4: Capillary rise of all samples in MD and $C D$ direction

\section{Resistance of coatings on printing surfaces}

To explore the relationship between the coatings and printing surfaces, the Cross test has been done (Figure 5). The results have shown that coatings and printing ink have influence on the surface. At coated samples it can be seen that small flakes of coatings have detached and intersections are seen. At sample 1, a cross area is from the measured standard, $5 \%$ affected, but still acceptable for the packaging purposes. At sample 2, small flakes of coating have detached along sides and at an intersections of the cut. A cross area between 5 and $15 \%$ was affected.

On the other hand, the uncoated samples showed that the edges of the cuts are completely smooth, none of the squares in the grid have detached. 


\begin{tabular}{|c|c|c|}
\hline Sample & Results after the test & Evaluation \\
\hline sample 1 - uncoated & & ISO 0; 5B \\
\hline sample 2 - uncoated & & ISO 0; 5B \\
\hline sample 1 - coated & & ISO 1; 4B \\
\hline sample 2 - coated & & ISO $2 ; 3 \mathrm{~B}$ \\
\hline
\end{tabular}

» Figure 5: Results of Cross test for uncoated and coted samples

\section{Conclusions}

In summary, we have developed a coating of chitosan, rosemary essential oil and paper to produce water resistant packaging material. The coated papers showed excellent water resistance (with $\mathrm{Cobb}_{60}$ values of 5.18 and $4.55 \mathrm{~g} / \mathrm{m}^{2}$ ). As expected, the results of the tensile and tear indices were higher in the samples in MD direction than in CD direction. The coated samples had the highest tensile and tear indices in both directions compared to the uncoated samples.

The resistance of the coatings verified the surface and coating resistance, with sample 1 having the worse results among all samples analysed. For packaging materials, water absorption and tensile properties are among the most important properties. Therefore, surface structuring has the potential to prove a fully effective coating on a biological basis as a potential in the field of repellent products, which will be analysed in the future. In order to improve the stability, migration and barrier properties of such papers, and this type of bio-based coating could still be combined with additional additives.

\section{References}

Atarés, L. \& Chiralt, A. (2016) Essential oils as additives in biodegradable films and coatings for active food packaging. Trends in food science \& technology. 48, 51-62. Available from: doi: 10.1016/j.tifs.2015.12.001

Da Silva, M. R. M. \& Ricci-Júnior, E. (2020) An approach to natural insect repellent formulations: from basic 
research to technological development. Acta Tropica. 105419. Available from: doi: $10.1016 / \mathrm{j}$.actatropica.2020.105419

Guerrero, A., Ferrero, S., Barahona, M., Boito, B., Lisbinski, E., Maggi, F. \& Sañudo, C. (2020) Effects of active edible coating based on thyme and garlic essential oils on lamb meat shelf life after long-term frozen storage. Journal of the Science of Food and Agriculture. 100

(2), 656-664. Available from: doi: 10.1002/jsfa.10061

Ju, J., Chen, X., Xie, Y., Yu, H., Guo, Y., Cheng, Y., Qian, H. \& Yao, W. (2019) Application of essential oil as a sustained release preparation in food packaging. Trends in Food Science \& Technology. 92, 22-32. Available from: doi: 10.1016/j.tifs.2019.08.005

Khwaldia, K., Arab-Tehrany, E. \& Desobry, S. (2010) Biopolymer coatings on paper packaging materials. Comprehensive reviews in food science and food safety. 9(1), 82-91. Available from: doi: 10.1111/j.15414337.2009.00095.x

Lee, J. Y., Jang, S., Aguilar, L. E., Park, C. H. \& Kim, C. S. (2019) Structural packaging technique using biocompatible nanofiber with essential oil to prolong the shelf-life of fruit. Journal of nanoscience and nanotechnology. 19(4), 2228-2231. Available from: doi: 10.1166/jnn.2019.15987

Licciardello, F., Muratore, G., Suma, P., Russo, A. \& Nerín, C. (2013) Effectiveness of a novel insect-repellent food packaging incorporating essential oils against the red flour beetle (Tribolium castaneum). Innovative Food Science \& Emerging Technologies. 19, 173-180. Available from: doi: 10.1016/j.ifset.2013.05.002

Lopez, S., Lima, B., Agüero, M. B., Lopez, M. L., Hadad, M., Zygadlo, J., Caballero, D., Suero, E., Feresin, G. \& Tapia, A. (2018) Chemical composition, antibacterial and repellent activities of Azorella trifurcata, Senecio pogonias, and Senecio oreophyton essential oils. Arabian journal of chemistry. 11(2), 181-187. Available from: doi: 10.1016/j.arabjc.2014.11.022

MArkets \& MArkets. (2020) Biopesticides Market by Type (Bioinsecticides, Biofungicides, and Bionematicides), Source (Microbials, Plant Extracts, and Beneficial Insects), Mode of Application, Formulation, Crop Application, and Region-Global Forecast to 2023. Available from: https://www.marketsandmarkets.com/Market-Reports/biopesticides/ [Accessed 9th March 2020]

Mossa, A. (2016) Green pesticides: Essential oils as biopesticides in insect-pest management. Journal of environmental science and technology. 9(5), 354-378. Available from: doi: 10.3923/jest.2016.354.378

Nollet, L. M. \& Rathore, H. S. (Eds.) (2017) Green pesticides handbook: Essential oils for pest control. Boca Raton, CRC Press. Available from: doi: 10.1201/9781315153131

Plata-Rueda, A., Martínez, L. C., Dos Santos, M. H., Fernandes, F. L., Wilcken, C. F., Soares, M. A., Serrão, J. E. \& Zanuncio, J. C. (2017) Insecticidal activity of garlic essential oil and their constituents against the mealworm beetle, Tenebrio molitor Linnaeus (Coleoptera: Tenebrionidae). Scientific reports. 7, 46406. Available from: doi: 10.1038/srep46406

Ribeiro-Santos, R., Andrade, M., De Melo, N. R. \& Sanches-Silva, A. (2017) Use of essential oils in active food packaging: Recent advances and future trends. Trends in food science \& technology. 61, 132-140. Available from: doi: 10.1016/j.tifs.2016.11.021
Rodriguez, A., Batlle, R. \& Nerin, C. (2007) The use of natural essential oils as antimicrobial solutions in paper packaging. Part II. Progress in Organic Coatings. 60(1), 33-38. Available from: doi: 10.1016/j.porgcoat.2007.06.006

Sánchez-González, L., Vargas, M., González-Martínez, C., Chiralt, A. \& Chafer, M. (2011) Use of essential oils in bioactive edible coatings: A review. Food Engineering Reviews. 3(1), 1-16. Available from: doi: 10.1007/ s12393-010-9031-3

Stejskal, V., Bostlova, M., Nesvorna, M., Volek, V., Dolezal, V. \& Hubert, J. (2017) Comparison of the resistance of mono-and multilayer packaging films to stored-product insects in a laboratory test. Food Control. 73(Part B), 566-573. Available from: doi: 10.1016/j.foodcont.2016.09.001

Tavares, M., da Silva, M. R. M., de Siqueira, L. B. D. O., Rodrigues, R. A. S., Bodjolle-d'Almeida, L., Dos Santos, E. P. \& Ricci-Júnior, E. (2018) Trends in insect repellent formulations: A review. International journal of pharmaceutics. 539(1-2), 190-209. Available from: doi: 10.1016/j.ijpharm.2018.01.046

Upadhyay, N., Dwivedy, A. K., Kumar, M., Prakash, B. \& Dubey, N. K. (2018) Essential oils as eco-friendly alternatives to synthetic pesticides for the control of Tribolium castaneum (Herbst)(Coleoptera: Tenebrionidae). Journal of Essential Oil Bearing Plants. 21(2), 282-297. Available from: doi: 10.1080/0972060X.2018.1459875

Vrabič Brodnjak, U. (2017) Experimental investigation of novel curdlan/chitosan coatings on packaging paper. Progress in Organic Coatings. 112, 86-92. Available from: doi: 10.1016/j.porgcoat.2017.06.030

Wang, H., Qian, J. \& Ding, F. (2018) Emerging chitosan-based films for food packaging applications. Journal of agricultural and food chemistry. 66(2), 395413. Available from: doi: 10.1021 /acs.jafc. $7 b 04528$

Yuan, G., Chen, X. \& Li, D. (2016) Chitosan films and coatings containing essential oils: The antioxidant and antimicrobial activity, and application in food systems. Food Research International. 89, 117-128. Available from: doi: 10.1016/j.foodres.2016.10.004 


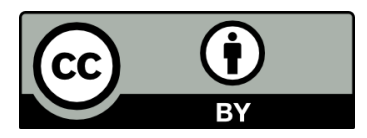

(C) 2020 Authors. Published by the University of Novi Sad, Faculty of Technical Sciences, Department of Graphic Engineering and Design. This article is an open access article distributed under the terms and conditions of the Creative Commons Attribution license 3.0 Serbia (http://creativecommons.org/licenses/by/3.0/rs/). 